\title{
Impact of reflecting land surface on radiation environment over Hornsund, Spitsbergen - a model study for cloudless skies
}

\author{
Anna ROZWADOWSKA ${ }^{1 *}$ and Izabela GÓRECKA ${ }^{2}$ \\ ${ }^{1}$ Institute of Oceanology, Polish Academy of Sciences, \\ ul. Powstańców Warszawy 55, 81-712 Sopot, Poland <ania@iopan.gda.pl> \\ 2 Geoterra, ul. Dąbrowszczaków 1, 80-374 Gdańsk, Poland <igorecka@geoterra.pl> \\ * corresponding author
}

\begin{abstract}
This paper addresses the influence of land topography and cover on 3D radiative effects under cloudless skies in the Hornsund area, Spitsbergen, Svalbard. The authors used Monte Carlo simulations of solar radiation transfer over a heterogeneous surface to study the impact of a non-uniform surface on: (1) the spatial distribution of irradiance transmittance at the fjord surface under cloudless skies; (2) the spectral shortwave aerosol radiative forcing at the fjord surface; (3) normalized nadir radiance at the Top Of the Atmosphere (TOA) over the fjord. The modelled transmittances and radiances over the fjord are compared to the transmittances and radiances over the open ocean under the same conditions. The dependence of the 3D radiative effects on aerosol optical thickness, aerosol type, surface albedo distribution, solar azimuth and zenith angle and spectral channel is discussed. The analysis was done for channels 3 (459-479 nm) and $2(841-876 \mathrm{~nm})$ of the MODIS radiometer. In the simulations a flat water surface was assumed. The study shows that snow-covered land surrounding the fjord strongly modifies the radiation environment over the fjord surface. The enhancement of the mean irradiance transmittance over the fjord with respect to the open ocean is up to 0.06 for channel 3 . The enhancement exceeds 0.11 in the vicinity of sunlit cliffs. The influence of the snow-covered land on the TOA radiance over the fjord in channel 3 is comparable to the impact of an increase in aerosol optical thickness of over $100 \%$, and in lateral fjords of up to several hundred percent. The increase in TOA radiance is wavelength dependent. These effects may affect retrievals of aerosol optical thickness.
\end{abstract}

Key words: Arctic, Svalbard, fjord, irradiance transmittance, aerosol radiative forcing, nadir radiance, Monte Carlo modelling. 


\section{Introduction}

Radiation that undergoes single or multiple reflection between the surface and the atmosphere is an important component of the solar radiation fluxes in the atmosphere over snow-covered areas, like mountains and the polar regions. In the Arctic, the surface albedo is high and at the same time highly variable. Moreover, the topography of land and coastal areas can be very complex.

The problems of the influence of high and variable surface albedo and/ or diverse topography on solar radiation fluxes at the Earth surface has been studied for various sites and regions and different parts of the solar spectrum (Degünther et al. 1998; Degünther and Meerkötter 2000; Kylling et al. 2000; Kylling and Mayer 2001; Rozwadowska and Cahalan 2002; Lubin et al. 2002; Huber et al. 2004; Lee et al. 2011; Rozwadowska and Górecka 2012; Kreuter et al. 2014). Both model analysis and measurements demonstrate the importance of surface properties to radiation fields at the Earth's surface and at the Top Of the Atmosphere (TOA), not only in cloudy conditions but also under cloudless skies. The highly reflective surface enhances horizontal photon transfer in the atmosphere. Lenoble (2000) found that photons reflected from the ground more than $30 \mathrm{~km}$ from the measurement point make a noticeable contribution to the ultraviolet zenith sky radiance under a clear sky. Smolskaia et al. (2003) performed a similar study with respect to downward irradiance. Their findings are in agreement with those of Lenoble (2000). Analysis of the time-patterns of ground-level solar irradiance during the solar eclipse of 29 March 2006 at three Italian stations (Lampedusa, Mt. Cimone and Bologna) also led to the conclusion that the incoming diffuse radiation recorded at these stations was affected by contributions from regions some $30-100 \mathrm{~km}$ distant from the stations (Petkov et al. 2010). In the ultraviolet spectral range, the impact distances have been found to be longer than those in the visible and near-infrared.

Lenoble et al. (2004) showed that the enhancement of the UV global irradiance due to snow cover on the ground at the Briançon station in a highaltitude Alpine valley depended on the snow distribution around the site and not on the topography. The distribution of snow determines horizontal photon transport due to reflection between the surface and the sky. However, topography can strongly influence solar radiation distribution by shading. The actual solar radiation reaching a slope also depends on its aspect and inclination. Szymanowski et al. (2008) showed that the mean monthly total solar radiation flux under clear skies in June in Wedel Jarlsberg Land, Spitsbergen, varied from nearly 50 to over $350 \mathrm{Wm}^{-2}$, depending on the location.

Non-uniform surface, including highly variable surface albedo, can pose problems in the modelling of solar radiation in the atmosphere. An application of Independent Column (or Pixel) Approximation approach (Marshak and Davis 2005), widely used in non-uniform situations, may lead to considerable biases in 
estimates of fluxes and radiances in the atmosphere. Strong net horizontal photon transport between columns or pixels, neglected in this method, leads to biased local estimates, especially for small pixels. If pixels are large the biases can be caused by negligence of surface non-uniformity within a pixel. For example surface non-uniformity is neglected in Global Circulation Models (GCMs). Chen et al. (2006) and Liou et al. (2007) determined the bias in surface solar radiation fluxes. Liou et al. (2007) performed Monte Carlo radiative transfer simulations for the Tibetan Plateau centred at the city of Lhasa. They found that the average surface solar flux over regional domains of $100 \times 100 \mathrm{~km}^{2}$ and $50 \times 50 \mathrm{~km}^{2}$ with highly variable topography can deviate from the smooth surface usually assumed in climate models and GCMs by $10-50 \mathrm{Wm}^{-2}$.

Strong horizontal photon transport also influences satellite and airborne measurements. Bélanger et al. (2007) studied the impact of ice field adjacency to a pixel under analysis on TOA radiance spectra. The ice adjacency effect led to large errors $\left(>0.002 \mathrm{sr}^{-1}\right)$ in the retrieval of normalised water-leaving radiance up to $24 \mathrm{~km}$ from the ice edge in the blue part of the spectrum $(443 \mathrm{~nm})$. Consequently, chlorophyll concentration retrievals for any pixel located within a distance of $10-20 \mathrm{~km}$ from the ice edge were unreliable for moderate to high chlorophyll concentrations $\left(>0.5 \mathrm{mg} \mathrm{m}^{-3}\right)$. Jäkel et al. (2013) used 3D Monte Carlo radiative transfer model to study the effects of the heterogeneity of surface reflectivity on the area-averaged surface albedo. They found that for moderate aerosol optical depth less than 0.4 and a wavelength range between 400 and $1000 \mathrm{~nm}$, the altitude and the heterogeneity of the surface albedo are the dominant factors determining the mean deviation between real local surface albedo and area-averaged albedo measured by an airborne radiometer.

The impact of the underlying surface on radiative transfer in the atmosphere depends on albedo distribution and topography. Therefore, the results of studies from one site can only be adopted at other localities if the conditions are similar. The aim of this paper is to estimate the influence of the land topography and cover on 3D radiative effects under cloudless skies in an Arctic coastal environment, based on the example of the Hornsund fjord region, Spitsbergen. This region was selected for study because it acts as a multidisciplinary research laboratory in the Arctic (e.g. Rozwadowska and Górecka 2012; Stempniewicz et al. 2013; Moskalik et al. 2014). The results of our study could be relevant to other projects, for example for projects related to topoclimate as well as remote sensing of the fjord and the atmosphere above the fjord region. The analysis is based on Monte Carlo simulations of solar radiation transfer over a non-uniform surface for channels $3(459-479 \mathrm{~nm}), 2(841-876 \mathrm{~nm})$ of the MODIS radiometer. The investigation focuses on the impact of a heterogeneous surface on: (1) the spatial distribution of irradiance transmittance at the fjord surface; (2) spectral shortwave aerosol radiative forcing at the fjord surface; (3) TOA nadir radiance over the fjord. The above-mentioned physical quantities over the fjord surrounded with 
the land are compared with these for the plane-parallel cases, i.e. over the open ocean under the same atmospheric conditions and the same solar positions. The present paper complements the paper by Rozwadowska and Górecka (2012). Both papers, Rozwadowska and Górecka (2012) and the present work, are the outcome of the project "A model study of the impact of a non-uniform land surface on selected aspects of solar radiation transfer in the Arctic atmosphere based an example of the Hornsund fjord region, Spitsbergen". They address similar problems, i.e. the impact of a non-uniform surface on solar radiation flux (irradiance transmittance) and radiative forcing at the fjord surface and nadir radiance at the TOA, but for different atmospheric conditions. The paper from 2012 concerns overcast skies. It discusses solar radiation distribution at the fjord surface under clouds, cloud radiative forcing at the fjord surface and nadir radiance over clouds at the TOA. The present paper deals with cloudless sky conditions and presents the impact of atmospheric aerosols on irradiance transmittance at the fjord surface and nadir radiance as well as aerosol radiative forcing in the heterogeneous Arctic environment. Both papers present results of the Monte Carlo radiative transfer model. However, in the present work the model was modified - gas absorption was added. Each of the papers is based on separate simulations.

\section{Materials and Methods}

Surface topography. - In this work, we used the Digital Elevation Model (DEM) of the Hornsund area described in Rozwadowska and Górecka (2012). The whole domain of the model is covered with a horizontal grid of $200 \mathrm{~m}^{2}$ cells. To each horizontal grid node the terrain height at this point was added as the third coordinate. The surface between four neighbouring nodes of the 3D grid was approximated by the following function (Ricchiazzi and Gautier 1998; Rozwadowska and Górecka 2012):

where:

$$
z=a_{0} \cdot x+a_{1} \cdot y+a_{2} \cdot x \cdot y+a_{3},
$$

$x, y$ and $z$ - the coordinates of a given point of a pixel (a 3D grid cell) surface, $a_{0}, a_{1}, a_{2}$ and $a_{3}$ - coefficients fitted to the coordinates of the cell nodes of the 3D grid.

The working DEM of the Hornsund area (Fig. 1) covers an area of $51.40 \mathrm{~km}$ $(\mathrm{X}$ axis, $\mathrm{W}-\mathrm{E}) \times 34.40 \mathrm{~km}(\mathrm{Y}$ axis $\mathrm{S}-\mathrm{N})$. We added a $20 \mathrm{~km}$ wide buffer belt to the main domain (working area) to diminish possible computation bias due to the cyclic borders of the domain in Monte Carlo simulations. 'The 'cyclic borders' mean that each photon which has left the domain through a side wall reenters it through the opposite wall. Thus the modelled region should be considered 


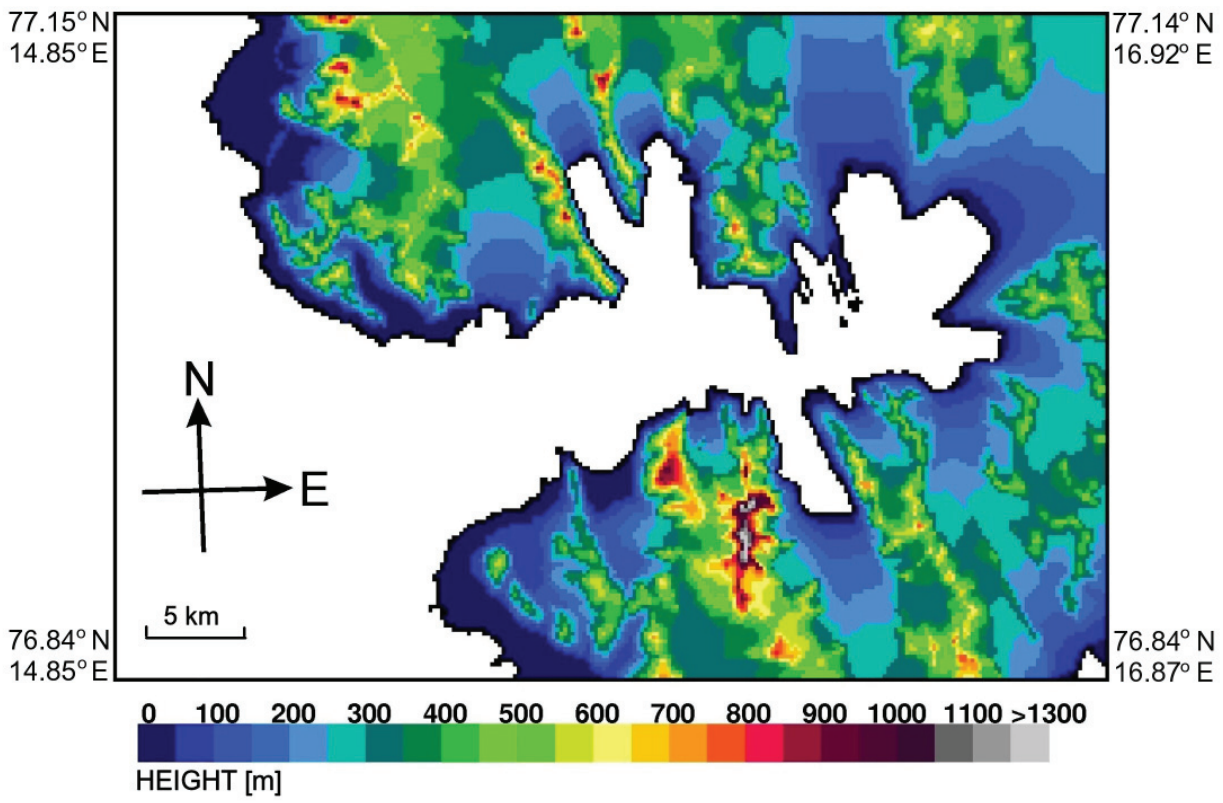

Fig. 1. Topography (Digital Elevation Model) of the main domain of the Monte Carlo simulations. UTM 33X projection, ellipsoid WGS84.

as a horizontally infinite mosaic of the main domain. If the distribution of surface albedo in the mosaic differs strongly from the real situation, the modelled radiative fluxes may be biased. The strongest bias is near the borders of the main domain. We may reduce it by surrounding the main domain with the buffer belt - the area with the real topography and albedo. The wider the buffer belts, the smaller the bias is in the main domain but the resulting total domain becomes larger then and more photons are necessary to obtain reliable results. The buffer belt used in our modelling is shown in Figure 2. The width of the belt was determined on the basis of numerical experiments.

Surface albedo parameterisation. - As in Rozwadowska and Górecka (2012), two extreme surface scenarios (or albedo patterns) - 'summer' and 'spring' - were used in this work. The spring pattern represents the land surface conditions which occur in late winter and spring in the Hornsund area. All the land is covered with snow then. Snow can persist until June (Styszyńska 2013; Niedźwiedź and Styszyńska 2013). Snow-covered land can be also observed in autumn. The summer pattern represents the lowest land albedo in the annual albedo cycle, which occurs in summer and early autumn, especially in August. In both albedo scenarios, the fjord and ocean are assumed to be ice-free to maximise the albedo contrast between the land and the sea. In such cases net horizontal 


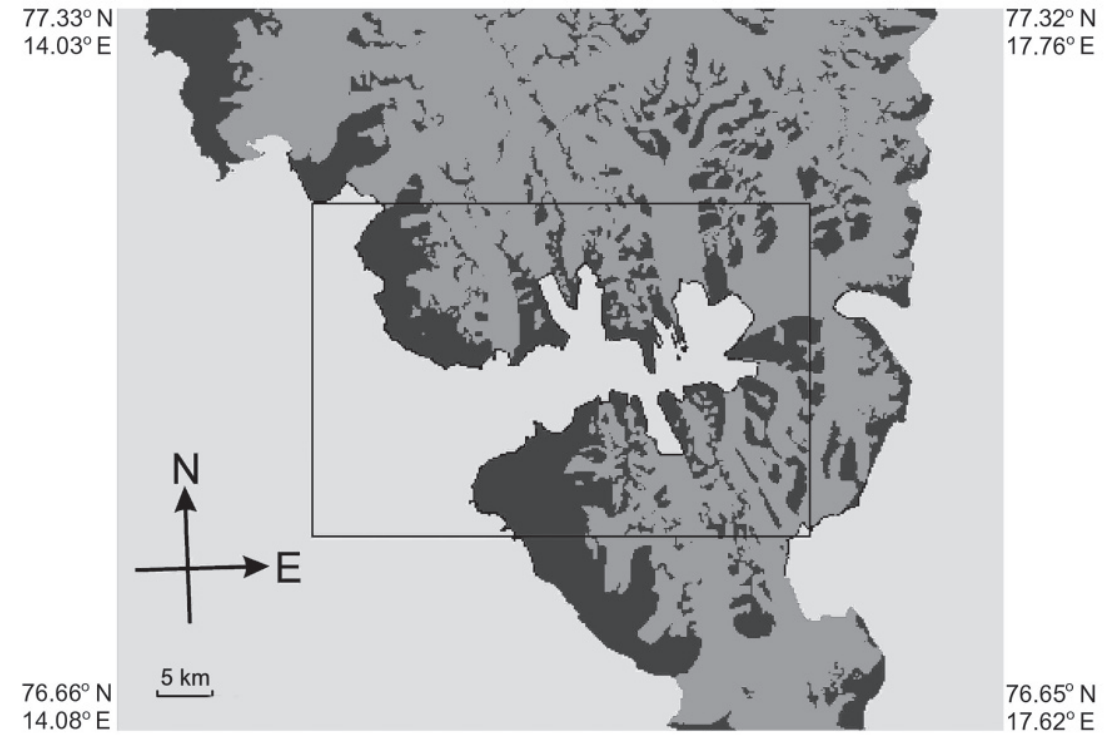

Fig. 2. Surface types used in the modelling. The main domain of the Monte Carlo simulations (working area) with the buffer belts is shown. Medium gray represents glaciers, dark gray shows mountains and coastal tundra and light gray denotes the sea surface. The black rectangle is the border of the main domain.

photon transport between the land pixels/grid cells and the fjord is expected to be the strongest. Using plane-parallel or independent pixel approximation approaches (e.g. Marshak et al. 1995) in the modelling of radiative transfer over the fjord can cause the largest errors. Ice-free or almost ice-free periods in Arctic fjords are expected to be longer and more frequent in a warming Arctic even in winter and spring.

Table 1 shows the spectral albedo of selected types of land surface used in the modelling. A distribution of surface types attributed to each grid cell: sea, glacier or tundra/rock is shown in Fig. 2. The methods of derivation of both the spectral albedo and the land type distribution are given in Rozwadowska and Górecka (2012). In our simulations we assumed a flat water surface and the specular reflection of photons from the water surface. We also assumed that the land surface was a Lambertian reflector in the modelling, regardless of the land cover.

Atmosphere. - In our calculations the model atmosphere is $60 \mathrm{~km}$ high and is divided into 26 homogeneous layers. The optical thickness of the topmost layer $(50-60 \mathrm{~km})$ is equal to the optical thickness of the $50-100 \mathrm{~km}$ layer in the Modtran 4 Subarctic Summer atmospheric model (Berk et al. 2003).

The optical properties of the atmosphere used in our simulations include gas absorption, Rayleigh scattering, as well as absorption and scattering by 
Table 1

Spectral albedo of the different types of surface used in the modelling (based on MODIS albedo products from 15 April 2007 and 13 August 2006).

\begin{tabular}{|l|c|c|c|}
\hline \multicolumn{1}{|c|}{ Surface type } & Surface albedo type & Wavelength $469 \mathrm{~nm}$ & Wavelength $858 \mathrm{~nm}$ \\
\hline \multirow{2}{*}{ Glacier $>150$ m a.s.l. } & spring & 0.87 & 0.79 \\
& summer & 0.57 & 0.47 \\
\hline \multirow{2}{*}{ Glacier $<150$ m a.s.l. } & spring & 0.87 & 0.77 \\
& summer & 0.43 & 0.37 \\
\hline \multirow{2}{*}{ Coastal tundra } & spring & 0.74 & 0.58 \\
& summer & 0.05 & 0.12 \\
\hline \multirow{2}{*}{ Mountains } & spring & 0.85 & 0.77 \\
& summer & 0.44 & 0.35 \\
\hline
\end{tabular}

atmospheric aerosols. Gas absorption in the spectral channels of MODIS was estimated using exponential sum fitting of transmission (e.g. Armbruster and Fischer 1996), a method commonly used to compute gas absorption in the atmosphere averaged over a given spectral interval. Gas absorption was added in this work. We computed gas transmittance functions for MODIS radiometer channels and for reference conditions $\left(p_{0}, T_{0}\right)$ with the Modtran code and approximated them by the sum of exponents. Functions relating the gas transmittances for the reference and real conditions were taken from Chou (1992). By expressing the gas transmittance as the sum of exponential terms, the radiative transfer computations can be performed independently on each term as if it were a monochromatic problem (Ricchiazzi et al. 1998).

The Rayleigh scattering coefficient was parameterised using the Callan formula (Thomas and Stamnes 2002, p. 73) and profiles of air temperature and pressure from May 2007 from Ny-Ålesund, Spitsbergen. The radio-sounding data for Ny-Ålesund were provided by AWI (Alfred Wegener Institute for Polar and Marine Research, Germany). For altitudes higher than $30 \mathrm{~km}$, averaged profiles for Subarctic Summer and Winter (Berk et al. 2003) were used.

For the model layers below $3 \mathrm{~km}$, Arctic aerosol optical properties from d'Almeida et al. (1991) were used. For the higher layers, tropospheric (3 to $10 \mathrm{~km}$ ) and stratospheric (10 to $30 \mathrm{~km}$ ) aerosol models from Modtran were adopted (Berk et al. 2003). D’Almeida et al. (1991) contains two Arctic aerosol models, called 'January' and 'July'. These models are intended to represent Arctic Haze aerosols ('January') and clean Arctic ('June') aerosols. We also used the 'January' model with the single scattering albedo SSA reduced to 0.94 . The optical properties of the aerosol models used in the present work are given in Table 2 for an aerosol optical thickness $\tau(550)=0.15$. The aerosol optical properties used in the Monte Carlo simulations are the attenuation coefficient, single scattering albedo and asymmetry factor of the scattering phase function. The mean humidity profile 
Table 2

The aerosol optical properties used in the radiative transfer modelling.

The reference aerosol optical thickness is $\tau(550)=0.15$.

The relative humidity near the surface is $76 \%$ (d'Almeida et al. 1991).

\begin{tabular}{|c|c|c|c|c|}
\hline Aerosol model & Wavelength [nm] & Optical thickness & $\begin{array}{c}\text { Single scattering } \\
\text { albedo near } \\
\text { the surface }\end{array}$ & $\begin{array}{c}\text { Asymmetry factor } \\
\text { albedo near } \\
\text { the surface }\end{array}$ \\
\hline January & 469 & 0.164 & 0.989 & 0.782 \\
\hline & 550 & 0.150 & 0.991 & 0.779 \\
\hline & 858 & 0.109 & 0.993 & 0.773 \\
\hline June & 469 & 0.155 & 0.856 & 0.720 \\
\hline & 550 & 0.150 & 0.894 & 0.710 \\
\hline & 858 & 0.137 & 0.919 & 0.708 \\
\hline
\end{tabular}

from Ny-Ålesund (April to September 2007) was used in the determination of aerosol properties. The aerosol scattering phase function was approximated using the Henyey-Greenstein function (Henyey and Greenstein 1941).

Radiative transfer model and modelled physical quantities. - A 3D forward Monte Carlo code was used to model radiative transfer in the 3D Arctic atmosphere (Marshak et al. 1995; Rozwadowska and Górecka 2012). The code is based on the 'maximum cross-section method of Marchuk et al. (1980). In this work, we added gas absorption.

Fluxes at the surface, expressed as irradiance transmittance and relative net irradiance, as well as normalised nadir radiance at the TOA were computed in this work.

The atmospheric transmittance of the downward irradiance at the fjord's surface $T_{E}$ was computed according to the equation:

$$
T_{E}=E_{s}^{r e l}=\frac{E_{s}}{E_{T O A}}=\frac{A_{p}}{A_{s} \cdot N_{T O A}} \sum_{j=1}^{N} w_{j},
$$

where:

$E_{s}$ - the downward irradiance at the fjord's surface in pixel/column $(\mathrm{k}, \mathrm{l})$,

$E_{T O A}$ - the downward irradiance at the TOA,

$N_{T O A}$ - the number of photons incident at the TOA $(\mathrm{k}, \mathrm{l})$,

$A_{s} \quad$ - the area of the Earth's surface within the pixel/column $(\mathrm{k}, \mathrm{l})$,

$A_{p} \quad$ - the area of the pixel $(\mathrm{k}, \mathrm{l})$,

$N-$ the number of photons reaching the Earth's surface within the pixel/ column $(\mathrm{k}, \mathrm{l})$,

$w_{j} \quad$ - the weight of the $j$-th photon reaching the Earth's surface within the pixel/column (k,l). 
The irradiance transmittance $T_{E}$ is also the relative irradiance $E_{s}{ }^{r e l}$ at the surface with respect to the irradiance at the TOA. Over the mountainous terrain we computed the relative irradiance $E_{s}{ }^{r e l}$ normal to the surface expressed by Eq. 2, but with $E_{s}$ being the downward irradiance aligned with the direction of the vector normal to the sloping surface. The relative irradiance normal to the inclined surface is not discussed in this work but it appears in Figures 4, 7 and 9.

The relative net irradiance $E_{n e t}^{r e l}$ at the fjord surface was computed in the same way as the relative irradiance or transmittance except that only photons absorbed by the surface were counted. Hence, $N$ in Eq. 2 would stand for the number of photons absorbed by the Earth's surface within the pixel/column $(\mathrm{k}, \mathrm{l})$, and $w_{j}$ would be the weight of the $j$-th photon absorbed by the Earth's surface within the pixel/column $(\mathrm{k}, \mathrm{l})$.

The shortwave direct aerosol radiative forcing or effect (ARF) at the Earth's surface is the difference between the net irradiance under a cloudless sky with an aerosol and without one (e.g. Markowicz et al. 2008). This definition is analogous to the definition of cloud radiative forcing and includes the direct impact of all aerosols, not just anthropogenic ones, on the surface shortwave radiative balance. In this paper, we analyse the spectral radiative forcing computed for channel 3 $(\lambda=469 \mathrm{~nm})$ of the MODIS radiometer, and expressed as the fraction of the TOA downward irradiance $E_{T O A}$ for the same time and geographical position. The spectral relative radiative forcing, $A R F_{\text {rel }}(\lambda)$, is defined as follows:

$$
A R F_{r e l}(\lambda)=\frac{\left(E_{d}^{a}(\lambda)-E_{u}^{a}(\lambda)\right)-\left(E_{d}^{0}(\lambda)-E_{u}^{0}(\lambda)\right)}{E_{T O A}(\lambda)}=E_{\text {net }}^{\text {rel,a }}(\lambda)-E_{\text {net }}^{r e l, 0}(\lambda),
$$

where:

$E$ - the upward (subscript 'u') and downward irradiances (subscript 'd') under a cloudless sky with an aerosol (superscript 'a') and without one (superscript ' 0 ');

$E_{n e t}^{\text {rel }}$ - relative net irradiance for aerosol (superscript 'a') and aerosol deprived cases (superscript ' 0 ').

According to such a definition the values of $A R F_{\text {rel }}$ are positive for surface warming and negative for surface cooling by aerosols.

The radiance measured by a satellite instrument was simulated using the 'local estimation' technique (Marchuk et al. 1980; Iwabuchi 2006). It is represented by the normalised radiance $I$ and given by the sum of all contributions at scattering events $i$ of photon $j$ in the atmospheric/domain column $(k, l)$, divided by the number of photons incident at the top of this column $N_{T O A}$, and multiplied by $\pi$ (adopted from Spada et al. 2006):

$$
I=\frac{\pi L_{T O A}}{E_{T O A}}=\frac{\pi}{N_{T O A}} \sum_{j=1}^{N_{T O A} N_{\text {sac }}(j)} \sum_{i=1}^{1} I_{i, j}
$$


In Eq. $4, E_{T O A}$ is the downward irradiance, $L_{T O A}$ is the nadir radiance at the TOA and $N_{s c a}(j)$ is the number of scattering events of photon $j$. The dimension of $I$ is $\mathrm{sr}^{-1}$.

Simulations and simulation uncertainties. - Computations were done for MODIS channels $3(459-479 \mathrm{~nm})$ and 2 (841-876 nm) using the Arctic aerosol models for the low troposphere up to $3 \mathrm{~km}$ ('January' and 'June' model; d'Almeida et al. 1991) and two patterns of surface albedo distribution ('spring' and 'summer'). In certain simulations, we used the 'January' model with the single scattering albedo reduced to 0.94 . The full list of the input parameters' employed in the simulations is given in Table 3. The number of photons used in a single run varies from $10^{6}$ for plane parallel cases (the open ocean) to $3 \times 10^{9}$ to $5 \times 10^{9}$ for most of the non-uniform cases (the fjord region).

In our simulations, the domain average statistical uncertainties of $T_{E}, E_{\text {net }}^{\text {rel }}$ and $I$ for a pixel, estimated using the method by Mayer (1999), do not exceed $1 \%, 1 \%$ and $2 \%$ respectively. The modelling results averaged over selected subregions of the main domain are discussed later in this paper. The locations of the subregions are given in Figure 3. The uncertainties of $T_{E}$ and $E_{n e t}^{r e l}$ for the subregions located in the fjord and the adjacent ocean do not exceed $0.2 \%$ and are usually below $0.1 \%$. The uncertainties of $I$ for the subregions are $<0.5 \%$.

The modelling results may be biased because of the cyclic borders of the domain. As mentioned above, we added a $20 \mathrm{~km}$ wide buffer belt to the main domain (working area) to diminish possible computation bias due to the cyclic borders of the domain in Monte Carlo simulations. Nevertheless, some biases are possible. They are expected to be the highest for a high land surface albedo, i.e. for the spring albedo pattern. They were estimated by comparing the modelling results for the main domain with a $20 \mathrm{~km}$ wide buffer belt and for the main domain with the buffer belt widened to $100 \mathrm{~km}$. The comparison was performed for wavelength $\lambda=469 \mathrm{~nm}$, aerosol optical thickness $\tau(550)=0.15$, solar zenith angle $\vartheta=60^{\circ}$ and solar azimuth $\alpha=180^{\circ}$. The estimated relative biases

Ranges of the input parameters used in the Monte Carlo modelling.

\begin{tabular}{|l|l|}
\hline Aerosol optical thickness & $0,0.04,0.08,0.15,0.30,0.50$ \\
\hline Aerosol models & January, June, January with SSA $=0.94$ \\
\hline Solar zenith angle $\left[^{\circ}\right]$ & $53,60,66,79$ \\
\hline Solar azimuth $\left[{ }^{\circ}\right]$ & 180 and $0,90,270$ \\
\hline Land surface albedo model & spring, summer \\
\hline Surface type & ocean (uniform), fjord region (non-uniform) \\
\hline
\end{tabular}




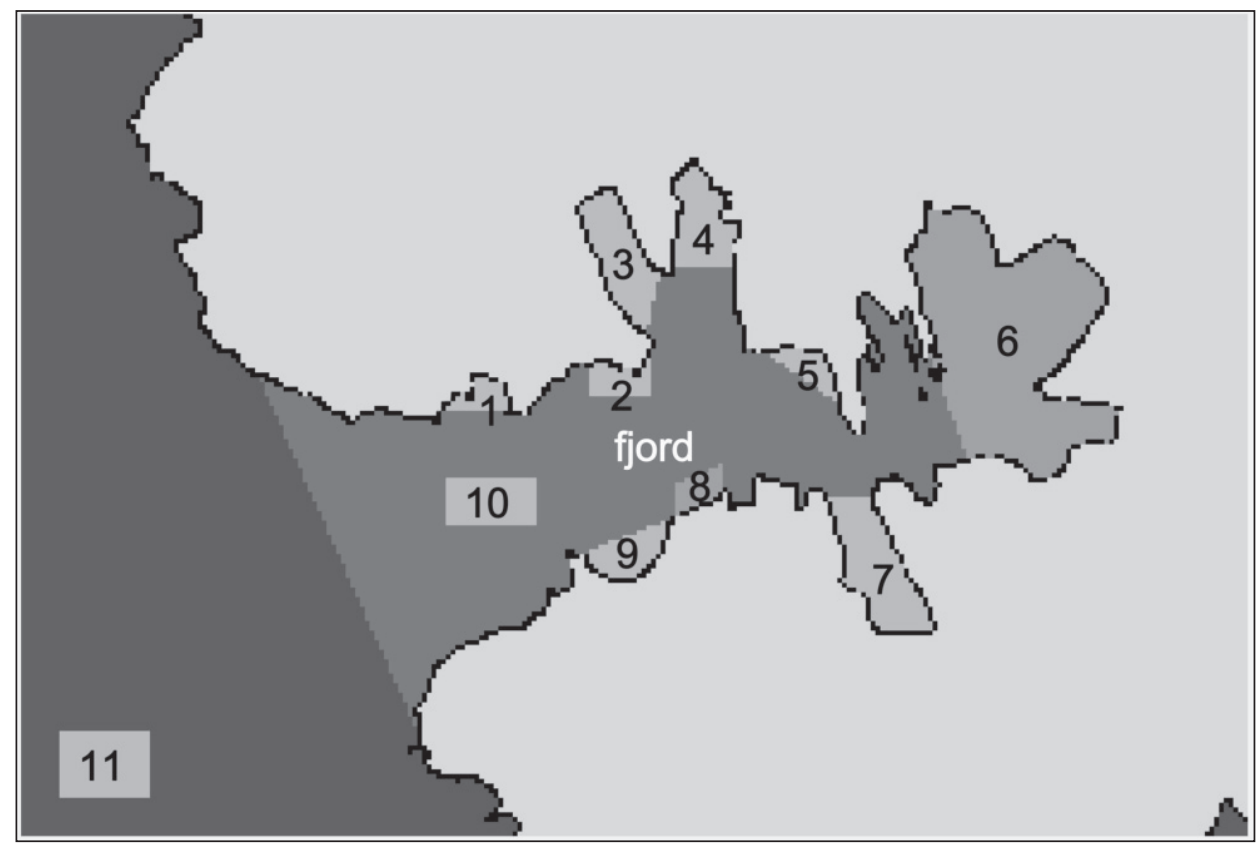

Fig. 3. Selected areas (subregions) for which the modelling data were averaged.

for the fjord region are $0.4 \%$ for $T_{E}$ and $E_{n e t}^{r e l}$ and $1 \%$ for $I$. The biases are expected to be lower for the summer albedo pattern and for MODIS channel 2 (841-876 $\mathrm{nm})$.

\section{Results and discussion}

In this section we discuss the impact of aerosol optical thickness, aerosol single scattering albedo, surface albedo distribution and solar zenith angle on surface distributions of the modelled atmospheric transmittance and aerosol spectral radiative forcing at the fjord surface as well as nadir radiances at the TOA over the fjord. The physical quantities over the fjord are compared with these over the open ocean under the same atmospheric conditions and the same solar position. If it were not for an impact of the land surrounding the fjord on the light field over the fjord, radiances, transmittances and aerosol forcing over the fjord would equal these quantities over the ocean in our modelling. Differences between the respective ocean and fjord values are called enhancements.

Eleven test areas were selected in the fjord and the adjacent ocean (Fig. 3). The subregions represent different areas: embayments (1 - Isbjornhamna with Hansbukta, 9 - Gashamna), waters abutting high cliffs $(2,5,8)$, inner fjords 
with a nearly north-south axis, terminating in glaciers (3 - eastern Burgerbukta, 4 - western Burgerbukta, 7 - Samarinvagen). Subregion 6 is the easternmost part of the Hornsund bordered by glaciers. Subregion 10 represents the central part of the western Hornsund. Subregion 11 is the ocean area where land influences are small or negligible.

Irradiance transmittance at the fjord surface. - The results of our simulations indicate that the irradiance transmittance or the relative downward irradiance, over the fjord depends strongly on the land surface albedo. Figure 4 exemplifies distributions of the transmittance at the fjord surface for two extremely different land albedo patterns: 'summer' (a) and 'spring' (b). Other conditions are the same in Figs $4 \mathrm{a}$ and $\mathrm{b}$ : aerosol optical thickness for $\lambda=550 \mathrm{~nm}$ and $\tau(550)=0.15$, 'January' aerosol model, solar zenith angle $\vartheta=60^{\circ}$, solar azimuth $\alpha=180^{\circ}$ and MODIS channel $3(\lambda=469 \mathrm{~nm})$. The noon-time solar zenith angle $\vartheta=60^{\circ}$ used in these simulations occurs on 8 May and 6 August. For comparison, the smallest solar zenith angle observed in the Hornsund area is $\vartheta=53^{\circ}$. The transmittance on the open ocean surface and under the same atmospheric conditions as in the simulations given in Fig. 4 is 0.812 . For the spring land albedo pattern (Fig. 4b) the mean transmittance enhancement over the fjord with respect to the open ocean is 0.053 . This value is comparable to the mean transmittance enhancement under overcast skies and for the cloud base at about $600 \mathrm{~m}$ and the same surface conditions (Rozwadowska and Górecka 2012). Like in the case of overcast skies, the local value of the clear sky enhancement depends on the distance from the shore and the
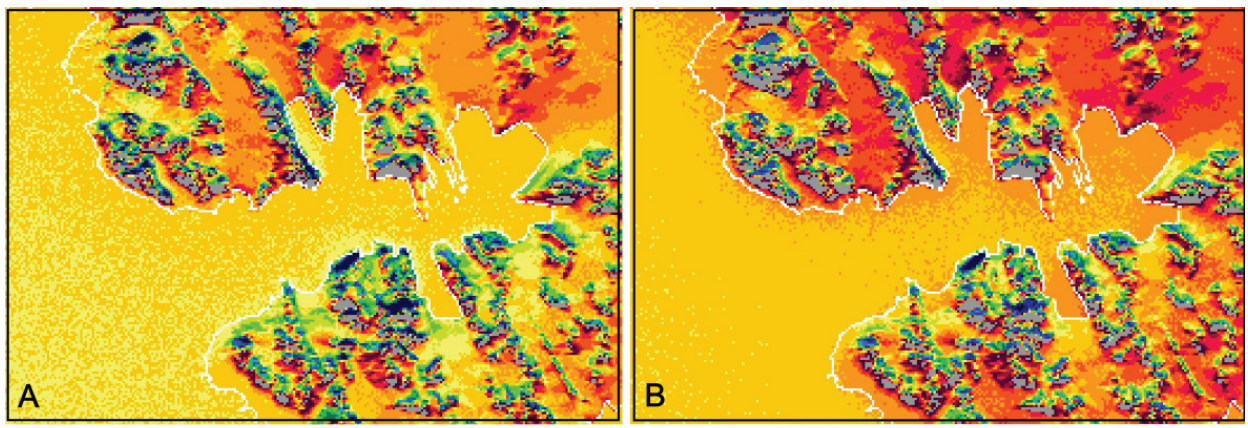

$\begin{array}{llllllllllll}0.26 & 0.34 & 0.42 & 0.50 & 0.58 & 0.66 & 0.74 & 0.82 & 0.90 & 0.98 & 1.06 & 1.14\end{array}$

SURFACE IRRADIANCE [rel. units]

Fig. 4. Distribution examples of relative irradiance normal to the surface in the Hornsund fjord region for an aerosol layer of $\tau(550)=0.15$ for the summer (a) and spring (b) albedo patterns, 'January' aerosol model, $\lambda=469 \mathrm{~nm}$ (MODIS channel 3), $\vartheta=60^{\circ}$ and $\alpha=180^{\circ}$. For horizontal surfaces (e.g. water) the relative irradiance normal to the surface is the atmospheric transmittance. 
shore topography. The transmittance enhancement $\Delta T_{E} \geq 0.016$, which is $2 \%$ of the ocean value, reaches a distance of about $10 \mathrm{~km}$ from the shore. Thus $\Delta T_{E} \geq 0.016$ is found over the whole fjord. The enhancement $\Delta T_{E} \geq 0.041$, which is $5 \%$ of the ocean value, is found in sunlit inner fjords and also up to $2-4 \mathrm{~km}$ from the sunlit shore. For the summer land albedo distribution the increase in transmittance is much lower in this spectral channel (Fig. 4a). The mean transmittance enhancement over the fjord with respect to the open ocean is 0.017 . The enhancement $\Delta T_{E} \geq 0.016(\geq 2 \%)$ is observed within about $2 \mathrm{~km}$ or less from sunlit rocky cliffs, near glaciers and in sunlit inner fjords. The enhancement of $5 \%$ or more occurs only at the close vicinity $(\leq 200 \mathrm{~m})$ of sunlit rocky cliffs and glacier fronts.

The surrounding land causes strong spatial variability of transmittance over the fjord. Our simulations indicate that for MODIS channel $3(\lambda=469 \mathrm{~nm})$ and snow-covered land the spatial variability of transmittance over the fjord is comparable to or higher than the variability of transmittance due to changes in aerosol optical thickness from 0.04 to 0.2 (Fig. 5a). For comparison, the daily mean aerosol optical thickness $\tau(500)$ measured in Hornsund in 2005-2008 varied from 0.05 to 0.2 in the Arctic Haze period (March to May) and from 0.03 to 0.12 from June to August. Higher values of $\tau(500)$ were very rare (Rozwadowska and Sobolewski 2010; Rozwadowska et al. 2010). Differences in $T_{E}$ between
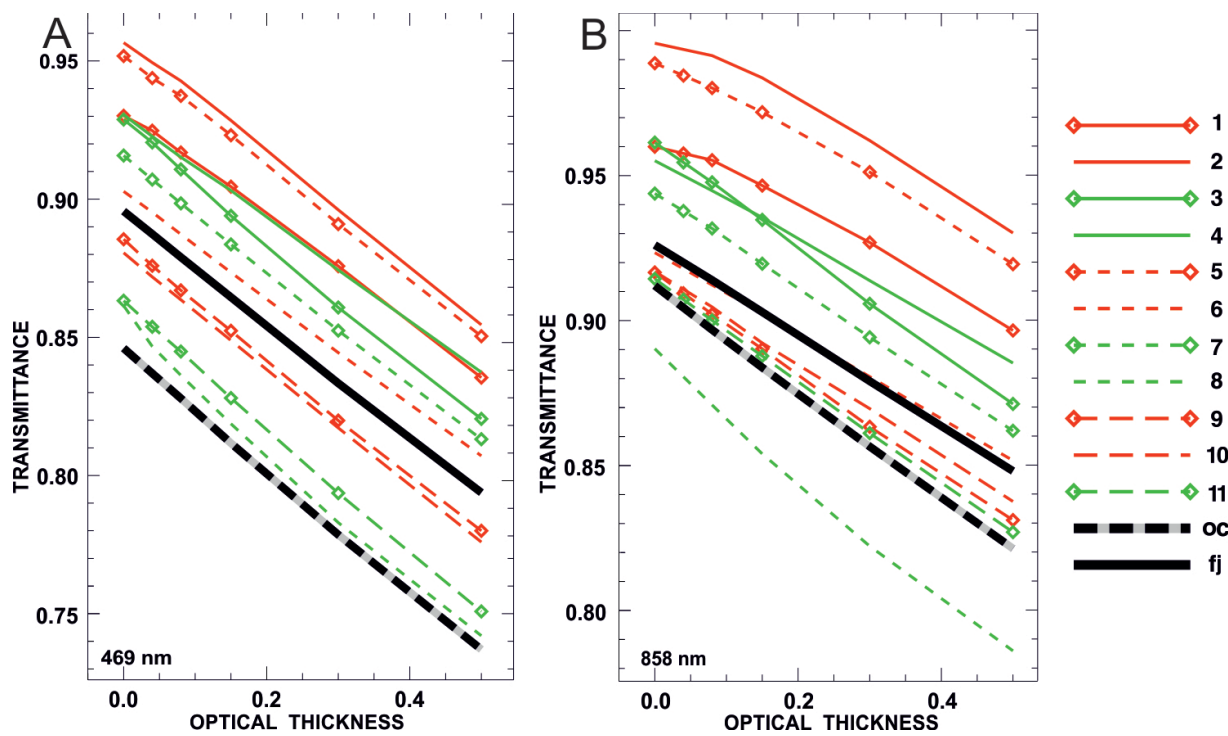

Fig. 5. Dependence of irradiance transmittance distribution at the fjord surface on the aerosol optical thickness; simulations for the spring albedo pattern, 'January' aerosol model, $\vartheta=60^{\circ}$, $\alpha=180^{\circ}$ and $\lambda=469 \mathrm{~nm}$ (A) and $\lambda=858 \mathrm{~nm}$ (B). The numbers in the legend are the subregion numbers from Fig. 3. Oc and fj denote ocean and fjord, respectively. 
the fjord subregions and the open ocean, i.e. transmittance enhancements, are nearly constant with $\tau$ when compared to their spatial variability. For $\lambda=469$ $\mathrm{nm}$ and $\tau(550)$ ranging from 0.04 to 0.50 , the mean transmittance enhancement over the whole fjord is $0.050-0.057$ (Fig. 5a; the spring albedo pattern, 'January' aerosol model, $\vartheta=60^{\circ}$ ). The maximum enhancement, found near the sun-lit cliffs (subregions 2 and 5) is about 0.11 . Relatively high enhancement values for the atmosphere without aerosols $(\tau(550)=0)$ indicate an importance of Rayleigh scattering for the transmittance enhancement over the fjord in channel 3.

For $\lambda=858 \mathrm{~nm}$ (Fig. $5 \mathrm{~b}$ ), both the spatial variability of irradiance transmittance over the fjord and the difference between the mean irradiance transmittance over the whole fjord and over the ocean are smaller. The mean transmittance enhancement is 0.014 for $\tau(550)=0$ and increases to 0.019 for $\tau(550)=0.15$ and 0.027 for $\tau(550)=0.50\left(\vartheta=60^{\circ}, \alpha=180^{\circ}\right.$, spring albedo pattern $)$. In this channel the snow albedo is only $10 \%$ lower than it is for $\lambda=469 \mathrm{~nm}$. Therefore, the differences between the channel 3 and 1 come mainly from lower molecular and aerosol scattering for $\lambda=858 \mathrm{~nm}$. Spectral dependency of $\Delta T_{E}$ results in elevated ratios $T_{E}(469) / T_{E}(858)$ over the fjord with respect to the open ocean. In the cases presented in Figure 5, the transmittance ratio is about 4\% higher over the fjord than it is over the open ocean.

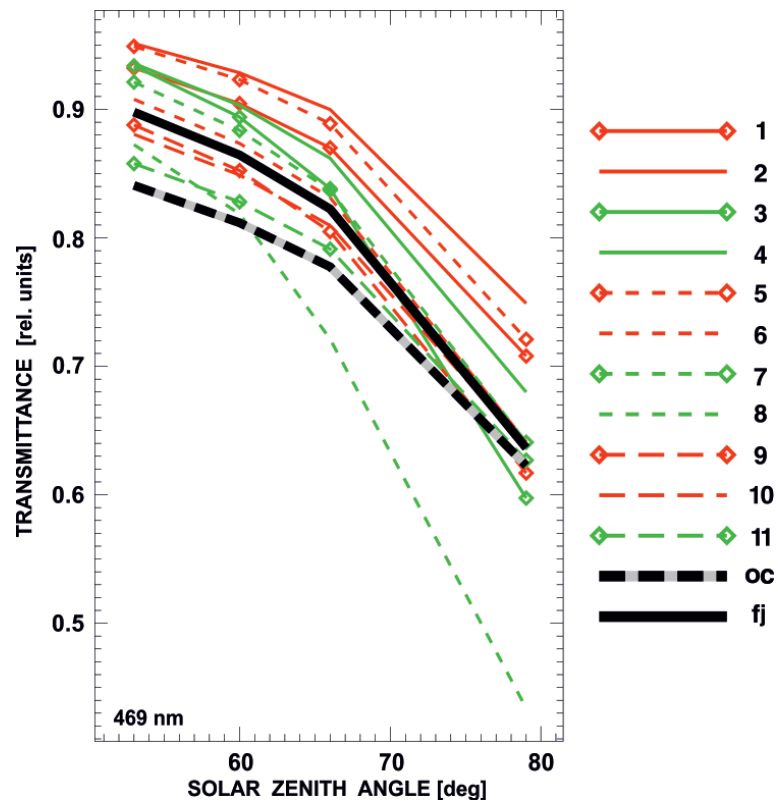

Fig. 6. Dependence of the irradiance transmittance distribution at the fjord surface on the solar zenith angle; simulations for the spring albedo pattern, 'January' aerosol model, $\lambda=469 \mathrm{~nm}$ (MODIS channel 3$), \alpha=180^{\circ}$ and $\tau(550)=0.15$. The numbers in the legend are the subregion numbers from Figure 3. Oc and fj denote ocean and fjord, respectively. 
The impact of the solar zenith angle on the mean irradiance transmittance in the subregions defined in Figure 3 is shown in Figure 6 for $\lambda=469 \mathrm{~nm}$, $\tau(550)=0.15$ and the spring land albedo pattern. For $\vartheta=53^{\circ}$ and $\tau(550)=0.15$ spatial differences in $T_{E}$ over the fjord are within 0.1. With an increase in solar zenith angle the difference in $T_{E}$ between the southern and northern parts of the fjord increases. At $\vartheta=79^{\circ}$ mountain shadows still cover only a small part of the fjord area. Apart from shading of the direct radiation by the mountains, the increase in spatial differentiation in $T_{E}$ is due to enhanced reflection from sun-facing cliffs and shading of the bright sky above the horizon (near the sun). Moreover, shaded land areas making a negligible contribution to incoming solar radiation are larger at $\vartheta=79^{\circ}$. An increase in the solar zenith angle from 53 to $79^{\circ}$ also reduces the difference between the ocean and the mean irradiance transmittance over the fjord, i.e. the mean transmittance enhancement, from 0.06 to 0.015 .

The results presented so far are for the solar azimuth $\alpha=180^{\circ}$ (measured clockwise of the north direction). The surface distribution of solar radiation at the Hornsund fjord surface also depends on the solar azimuth. An example of the distribution differences is shown in Fig. 7 (spring albedo pattern, 'January' aerosol model, $\lambda=469 \mathrm{~nm}, \tau(550)=0.15, \vartheta=79^{\circ}$ and $\alpha=0^{\circ}, \alpha=90^{\circ}, \alpha=180^{\circ}$ and $\alpha=270^{\circ}$ ). The highest difference between the mean irradiance transmittances over the fjord

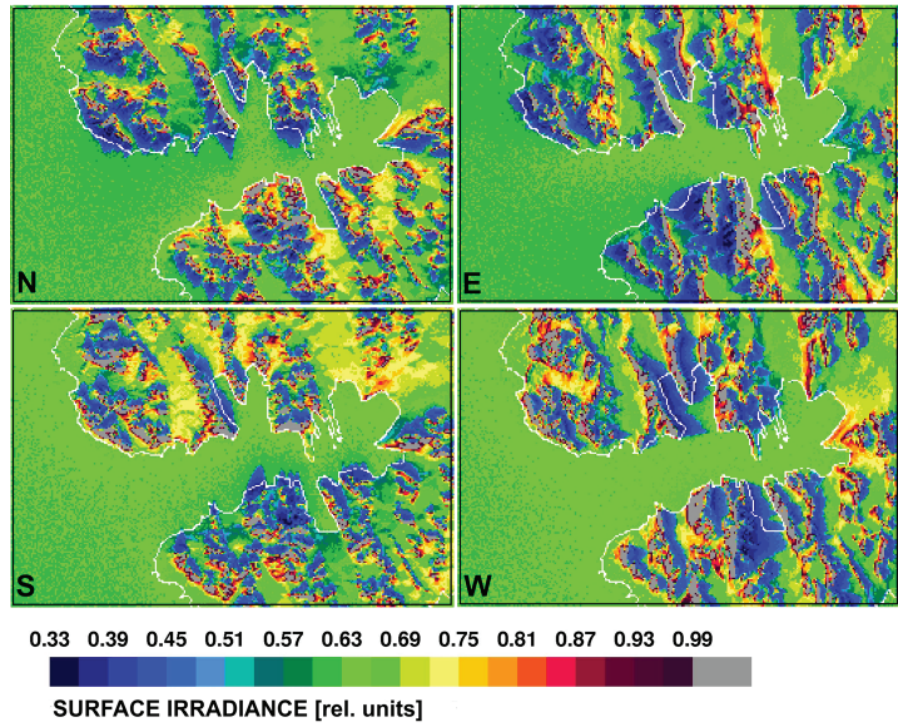

Fig. 7. Dependence of the distribution of relative irradiance normal to the surface in the Hornsund fjord region on the solar azimuth. Input parameters: $\tau(550)=0.15$, 'January' aerosol model, spring albedo pattern, $\lambda=469 \mathrm{~nm}$ (MODIS channel 3), $\vartheta=79^{\circ}$ and $\alpha=0^{\circ}(\mathrm{N}), 90^{\circ}(\mathrm{E}), 180^{\circ}(\mathrm{S})$ and $270^{\circ}(\mathrm{W})$. For horizontal surfaces (e.g. water) the relative irradiance normal to the surface is the atmospheric transmittance. 
and the ocean is found for $\alpha=180^{\circ}\left(0.013\right.$ for $\vartheta=79^{\circ}, 0.045$ for $\left.\vartheta=66^{\circ}\right)$ when shading of the lateral fjords is relatively low. The southerly position of the sun also results in the highest variability in irradiance transmittance among the subregions $\left(0.32\right.$ for $\vartheta=79^{\circ}, 0.18$ for $\left.\vartheta=66^{\circ}\right)$. The irradiance transmittance in the central part of the fjord, represented by subregion 10, depends only weakly on the solar azimuth. It increases from the northern to the western solar positions and varies respectively from 0.626 to 0.648 for $\vartheta=79^{\circ}$ and from 0.804 to 0.814 for $\vartheta=66^{\circ}$. Even though the mean irradiance transmittance over the fjord and $T_{E}$ in the central part of the fjord depend only weakly on the solar azimuth, this strongly influences $T_{E}$ in the lateral fjords.

We have presented model results for a weakly absorbing aerosol so far. If we increase the aerosol absorption by reducing the single scattering albedo to 0.94 in the 'January' model or applying 'June' aerosol model, the mean enhancement of irradiance transmittance for the fjord area decreases by up to about $10 \%$ for aerosol optical thickness $\tau(550)<0.2$ (simulation for $\lambda=469 \mathrm{~nm}$, $\vartheta=60^{\circ}$ and the spring albedo pattern).

Aerosol radiative effect. - In this section, we analyse the spectral radiative forcing, $A R F_{r e l}(469)$, computed for channel $3(\lambda=469 \mathrm{~nm})$ of the MODIS radiometer, and expressed as the fraction of the TOA downward irradiance $E_{T O A}$ for the same time and geographical position (Eq. 3). Radiative forcing $A R F_{r e l}(469)$ of Arctic aerosols over the fjord is typically negative, which means that they cool the surface. Its magnitude over the Hornsund fjord (averaged over the fjord) for $\vartheta=60^{\circ}, \alpha=180^{\circ}$, weakly absorbing aerosol ('January' model) and the spring albedo pattern changes from 0.009 for the summer background value of the aerosol optical thickness $(\tau(550)=0.04)$ to 0.034 for $\tau(550)=0.15$ and 0.102 for the extremely high aerosol optical thickness $(\tau(550)=0.5)$ (Fig. 8a).

The magnitude of the mean $A R F_{\text {rel }}(469),\left|<A R F_{\text {rel }}(469)>\right|$, for the whole fjord is smaller than it is for the open ocean under the same conditions, but the difference does not exceed 0.003 for the aerosol optical range from 0.04 to 0.15 , typical of the Arctic, and weakly absorbing aerosols. For the individual subregions the differences between $A R F_{r e l}(469)$ and the ocean value, the $A R F_{\text {rel }}$ enhancements, exceed \pm 0.01 only for large solar zenith angles $\left(\vartheta=79^{\circ}\right)$. Some fjord areas can have $A R F_{\text {rel }}(469)$ lower (the absolute value $\left|A R F_{\text {rel }}(469)\right|$ larger) than the ocean. Shaded areas for low zenith angles and polygons next to sunlit cliffs for high zenith angles belong to such cases.

The difference of $A R F_{\text {rel }}(469)$ from the respective ocean value decreases a little for the stronger absorbing aerosols. For the reduced single scattering albedo (SSA(469)=0.94; not shown in a figure) the enhancements are 0.001-0.002 lower.

An increase in the aerosol optical thickness enhances the spatial variability of $A R F_{r e l}(469)$ over the fjord. The spatial variability also increases for low solar positions $\left(\vartheta=79^{\circ}\right)$, when the differences between $A R F_{\text {rel }}(469)$ for the individual 

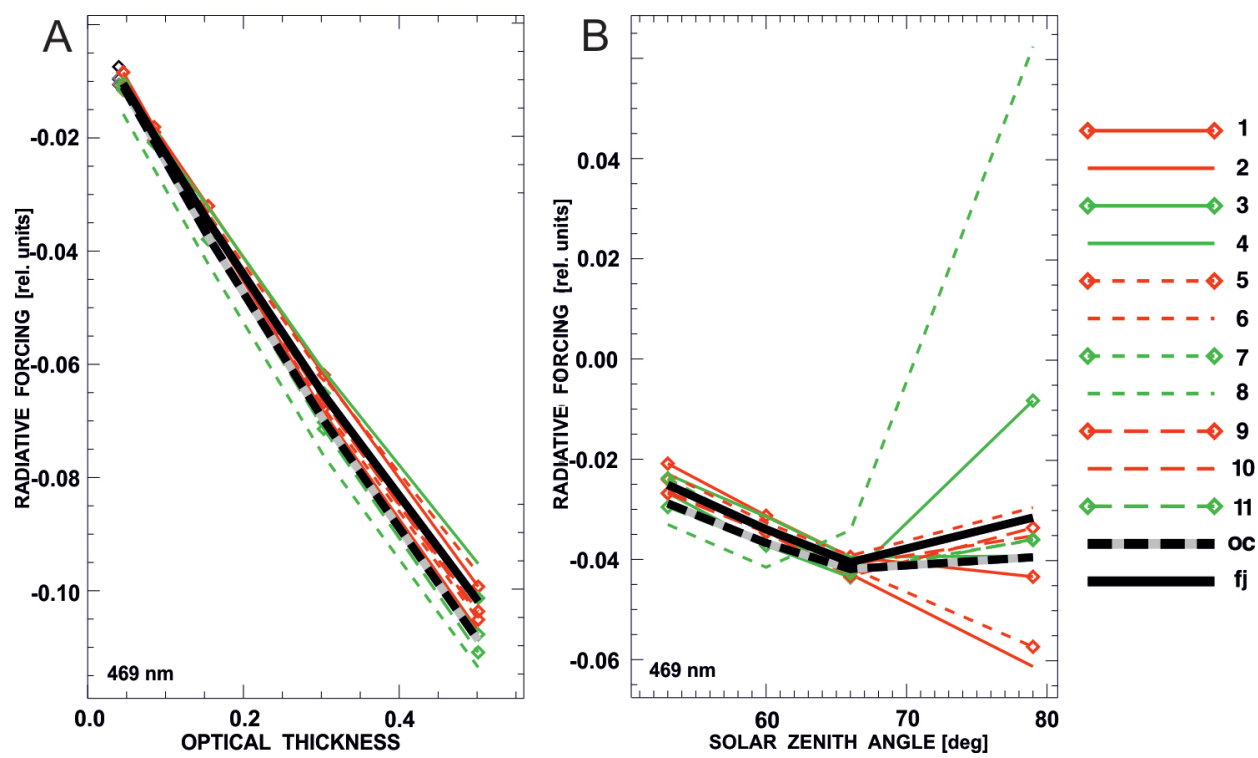

Fig. 8. Dependence of the aerosol spectral relative radiative forcing $A R F_{\text {rel }}(\lambda=469 \mathrm{~nm})$ at the fjord surface on the aerosol optical thickness (A) and the solar zenith angle (B); simulations for the spring albedo pattern, 'January' aerosol model, $\lambda=469 \mathrm{~nm}$ (MODIS channel 3), $\alpha=180^{\circ}$, and $\vartheta=60^{\circ}$ (A) and $\tau(550)=0.15$ (B). The numbers in the legend are the subregion numbers from Fig. 3. Oc and fj denote ocean and fjord, respectively.

subregions can exceed 0.12 for weakly absorbing aerosols and $\tau(550)=0.15$ (Figure 8b). Under a low sun, atmospheric aerosols enhance the irradiance diffusivity, and thus the mean cosine of the zenith angle of the incoming radiation increases and the water albedo decreases. This results in an increase in $A R F_{r e l}(469)$. For strongly shaded areas, lit by diffused radiation only, $A R F_{r e l}(469)$ can become positive (subregion $8, A R F_{r e l}(469)=0.062$ ). For subregions abutting sunlit cliffs (subregions 5 and 2), however, $A R F_{\text {rel }}(469)$ consistently decreases with $\vartheta$ for $\vartheta$ up to $79^{\circ}$.

Nadir radiances at the TOA over the fjord. - The impact of 3D photon transport in the Arctic atmosphere on remote sensing of the atmosphere over the fjord was studied using the normalised nadir radiance at the TOA calculated by Eq. 4. The radiance backscattered by the fjord bottom, water constituents and the water itself was assumed to be zero.

The normalised nadir radiance distribution over the fjord is shown in Fig. 9 for an aerosol layer of $\tau(550)=0.15$, weakly absorbing aerosol ('January' model), the spring land albedo pattern, $\lambda=469 \mathrm{~nm}$ (MODIS channel 3), $\vartheta=79^{\circ}$ and $\alpha=0$, 90,180 and $270^{\circ}$. In this simulation the radiance over the fjord varies from $0.20 \mathrm{sr}^{-1}$ to $0.25 \mathrm{sr}^{-1}$ and is up to $0.055 \mathrm{sr}^{-1}$ higher than it is over the open 

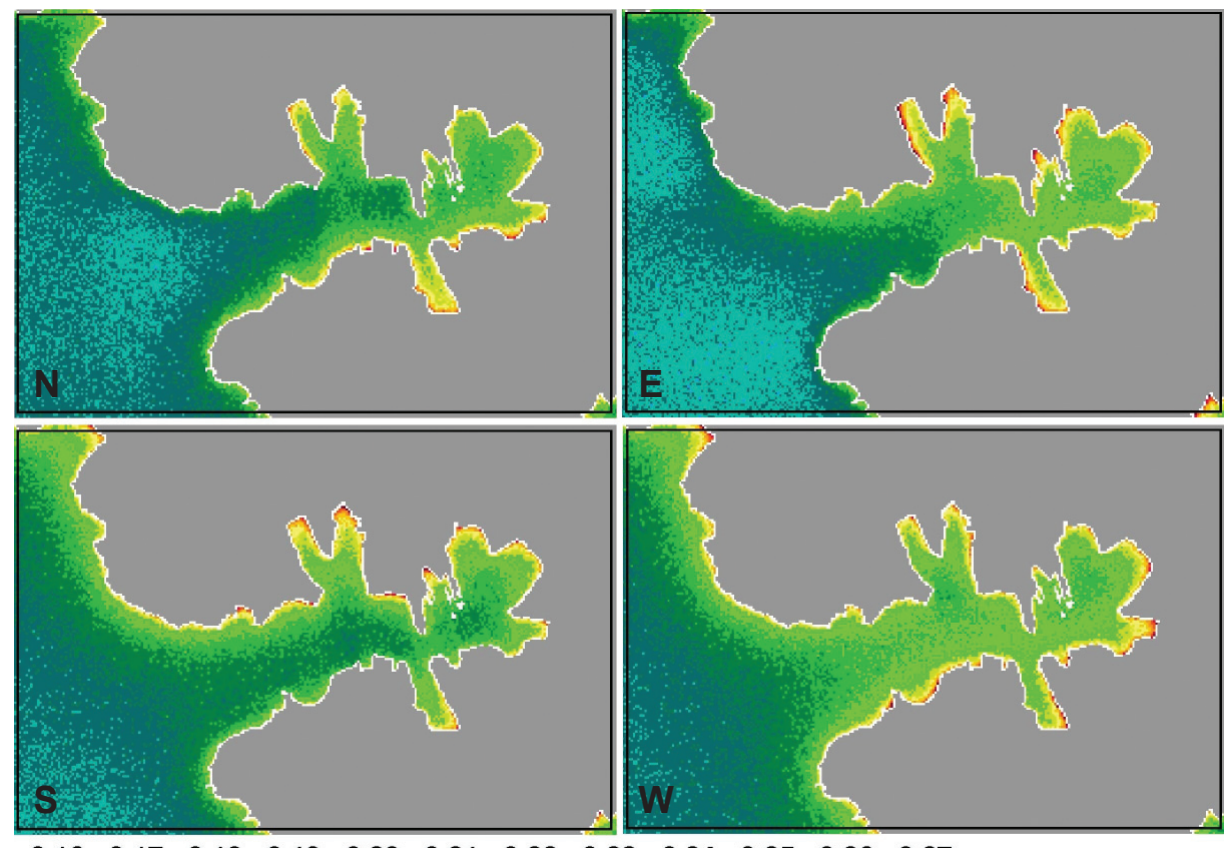

$\begin{array}{llllllllllll}0.16 & 0.17 & 0.18 & 0.19 & 0.20 & 0.21 & 0.22 & 0.23 & 0.24 & 0.25 & 0.26 & 0.27\end{array}$

\section{TOA NADIR RADIANCE $\left[\mathrm{sr}^{-1}\right]$}

Fig. 9. Dependence of the normalised nadir radiance distribution at the TOA on the solar azimuth. The input parameters are: $\tau(550)=0.15$, 'January' aerosol model, spring albedo pattern, $\lambda=469 \mathrm{~nm}$ (MODIS channel 3), $\vartheta=79^{\circ}$ and $\alpha=0^{\circ}(\mathrm{N}), 90^{\circ}(\mathrm{E}), 180^{\circ}(\mathrm{S})$ and $270^{\circ}(\mathrm{W})$. The radiance over the open ocean is 0.195 .

ocean. The range of variability of the radiance is similar for each azimuth but the radiance at the mouth of the fjord and in its central part is the highest for the western sun. For this solar position the impact of the land on the irradiance over the water is seen throughout the domain.

The dependence of the nadir radiance on the aerosol optical thickness is illustrated in Fig. 10 for the spring land albedo pattern, $\lambda=469$ and $858 \mathrm{~nm}$ (MODIS channels 3 and 2 respectively), $\vartheta=60^{\circ}$ and $\alpha=180^{\circ}$. This dependence is very weak, much weaker than the spatial variability of the radiance over the fjord. For the aerosol optical thickness range $\tau(550)=0.04-0.15$, typical of the Hornsund region, and $\lambda=469 \mathrm{~nm}$, the nadir radiance over the fjord (selected subregions) is higher by $0.018-0.056 \mathrm{sr}^{-1}$ than it is over the open ocean. When the TOA radiance is expressed as the aerosol optical thickness using the dependence of $\tau(\mathrm{I})$ for the open ocean from Fig. 10a, we observe the $\tau(550)$ apparent enhancement over the fjord with respect to the real $\tau(550)$. The enhancement varies from 0.16 to $>0.5$. In this case the difference between the real aerosol optical thickness and the aerosol optical thickness 'retrieved' using the oceanic relation from Figure 10a 

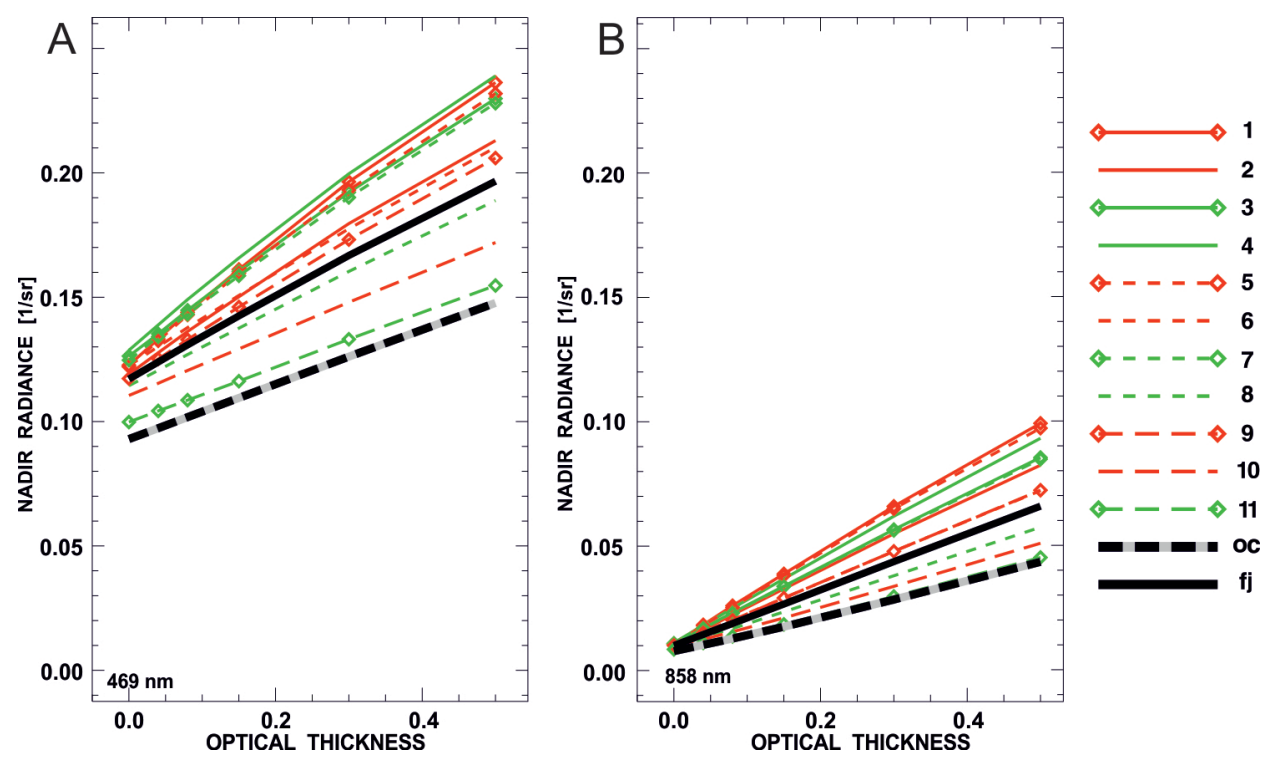

Fig. 10. Dependence of the normalised nadir radiance at the TOA on the aerosol optical thickness; simulations for the spring albedo pattern, 'January' aerosol model, $\vartheta=60^{\circ}, \alpha=180^{\circ}$ and $\lambda=469 \mathrm{~nm}(\mathbf{A})$ and $\lambda=858 \mathrm{~nm}(\mathbf{B})$. The numbers in the legend are the subregion numbers from Fig. 3. Oc and fj denote ocean and fjord, respectively.

exceeds $100 \%$. For $\lambda=858 \mathrm{~nm}$ the TOA radiances are lower (Figure 10b). Nevertheless, the radiance enhancements over the subregions varies from 0.002 to $0.021 \mathrm{sr}^{-1}$ for the aerosol optical thickness range $\tau(550)=0.04-0.15$, which, expressed as the apparent enhancement in aerosol optical thickness, is from 0.03 to about 0.3 .

Under low sun conditions, differences in the TOA radiance over different parts of the fjord and between the fjord and the open ocean decrease (Fig. 11). For the spring albedo pattern, $\tau(550)=0.15, \lambda=469 \mathrm{~nm}, \vartheta=79^{\circ}$ and $\alpha=180^{\circ}$, the nadir radiance enhancement over the fjord subregions with respect to the ocean varies from 0.005 to $0.036 \mathrm{sr}^{-1}$, which is equal to an apparent enhancement of $\tau$ from 0.03 to $>0.3$.

Changing the land albedo to summer conditions also diminishes the apparent enhancement of $\tau$ over the fjord. For $\tau=0.04-0.15, \lambda=469 \mathrm{~nm}, \vartheta=60^{\circ}$ and $\alpha=180^{\circ}$, the differences in TOA nadir radiance between fjord subregions and the ocean are in the range of $0.006-0.023 \mathrm{sr}^{-1}$ and $\Delta \tau=0.05-0.21$.

In our simulations, an increase in aerosol absorption weakly enhances $\Delta \tau$. However, it slightly reduces radiances over the fjord. For the aerosol optical thickness range $\tau(550)=0.04-0.15$ and the 'January' aerosol model with SSA lowered to 0.94 (spring land albedo pattern, $\lambda=469 \mathrm{~nm}, \vartheta=60^{\circ}$ and $\alpha=180^{\circ}$ ), radiances over the fjord are lower by less than $3 \%$ than they are in the case 


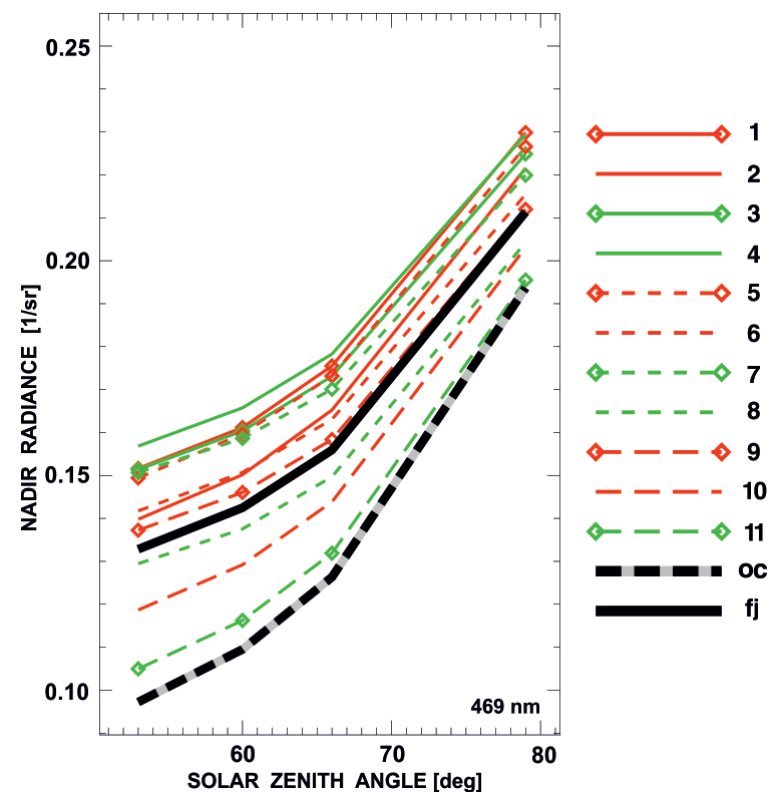

Fig. 11. Dependence of the nadir radiance at the TOA on the solar zenith angle; simulations for $\tau(550)=0.15$, spring albedo pattern, 'January' aerosol model, $\vartheta=60^{\circ}, \alpha=180^{\circ}$ and $\lambda=469 \mathrm{~nm}$. The numbers in the legend are the subregion numbers from Fig. 3. Oc and fj denote ocean and fjord, respectively.

when SSA=0.99. For the July aerosol model the differences do not exceed $4.5 \%$. In the cases with absorbing aerosol the apparent enhancement of aerosol optical thickness for this $\tau$ range is slightly higher than the enhancement for weakly absorbing aerosols. For example for SSA $=0.94$ and $\tau(550)=0.04-0.15$ the nadir radiance over the fjord is from 0.018 to $0.054 \mathrm{sr}^{-1}$ higher than it is over the open ocean, which results in an aerosol optical thickness enhancement $\Delta \tau$ of from 0.18 for the central part of the fjord (subregion 11) and $\tau=0.04$ to $>0.5$ for $\tau=0.15$ and subregions $2,4,5,6$ and 8 (mainly sunlit inner fjords).

The increase in radiance over the fjord due to reflecting land surrounding it have implications for the remote sensing of aerosol properties. Here we discuss the TOA radiance distributions over the Hornsund fjord for channels 3 and 2 of the MODIS radiometer. The ocean MODIS algorithm uses MODIS channels from the spectral range 550-2130 nm: $4(545-565 \mathrm{~nm}), 1(620-670 \mathrm{~nm})$, $2(841-876 \mathrm{~nm}), 5(1230-1250 \mathrm{~nm}), 6(1628-1652 \mathrm{~nm})$ and $7(2105-2155 \mathrm{~nm})$. Channel 3 is not used in the selection of aerosol type or the determination of aerosol optical thickness over the water (Remer et al. 2005). It is only used in the part of the algorithm dedicated to sun glint detection. The results obtained in this work can be interpolated to channel 4 and channel 1, which are used in the main algorithm. In both these channels the land surface albedo is similar 
to those in channel 3. The snow albedo is only a few per cent lower. Both Rayleigh and aerosol scattering are still considerable. In channels 4 and 1 the Rayleigh scattering coefficient makes up 53 and $26 \%$ of the Rayleigh scattering coefficient respectively for channel 3 . For comparison, the Rayleigh scattering coefficient of channel 2 is $8.5 \%$ of the coefficient for channel 3 . The respective aerosol scattering coefficients for channels 4,1 and 2 are 93,84 and $70 \%$ of this coefficient for channel 3 . Given the above and the results of our modelling we may presume that as in channel 3 , the TOA radiance over the fjord increases considerably in MODIS channels 4 and 1 when the land surrounding the fjord is covered with snow. A similar effect occurs near glaciers or sea ice. This increase is comparable to the effect of an increase in aerosol optical thickness over the ocean even by more than $100 \%$ and in lateral fjords even by several hundred per cent.

Because of the dependence on wavelength of both the atmospheric scattering and the surface albedo, the impact of the land on aerosol retrieval over an Arctic fjord decreases with wavelength. It should be small for wavelengths longer than $0.87 \mu \mathrm{m}$. In channels $6(1628-1652 \mathrm{~nm})$ and $7(2105-2155 \mathrm{~nm})$ it is negligible. In effect, the TOA spectrum over the fjord turns more bluish, and this may seriously affect retrievals of aerosol optical properties over the water in the coastal region of the Arctic near glaciers and snow-covered land. It can influence both the selection of aerosol model by the remote sensing algorithm and the retrieved aerosol optical thickness.

Snow and ice present in and around fjords are not the only concern regarding the influence of $3 \mathrm{D}$ radiative transfer effects on space-based inferences of downward shortwave irradiances and aerosol properties over oceans. The closeness of clouds to cloud-free ocean pixels, even over the open ocean, exhibits many of the same effects as reported in this paper (Marshak et al. 2008; Várnai and Marshak 2009).

\section{Conclusions}

In our simulations, the highest irradiance transmittance enhancement over the fjord with respect to the open ocean is found for a relatively high aerosol optical thickness, weakly absorbing aerosols, a low solar zenith angle, a high land albedo and channel $3(\lambda=469 \mathrm{~nm})$ of the MODIS radiometer. However, the highest surface variability of the enhancement is found for a low sun. For the range of aerosol optical thicknesses typical of the Arctic, i.e. $\tau$ from 0.04 to 0.15 , the spring albedo pattern (snow-covered land), solar zenith angle $\vartheta=60^{\circ}$, solar azimuth $\alpha=180^{\circ}$ and channel $3(\lambda=469 \mathrm{~nm})$ of the MODIS radiometer, the mean irradiance transmittance enhancement over the fjord with respect to the open ocean, i.e. the difference between the mean transmittances over the whole fjord and the ocean, is about 0.05 . For the summer land albedo distribution the 
mean enhancement is much lower in this spectral channel $\left(0.017\right.$ for $\vartheta=60^{\circ}$, $\alpha=180^{\circ}$ and $\left.\tau(550)=0.15\right)$.

The mean transmittance and its enhancement for the fjord decrease with increasing solar zenith angle $\vartheta$ and aerosol absorption. An increase in solar zenith angle from $53^{\circ}$ to $79^{\circ}$ results in a reduction of the mean enhancement for the fjord from 0.06 to 0.015 for the spring albedo pattern $(\lambda=469 \mathrm{~nm}, \tau(550)=0.15)$. For $\lambda=858 \mathrm{~nm}$ (channel 2 of the MODIS radiometer), both the spatial variability of transmittance over the fjord and the mean transmittance enhancement with respect to the open ocean are smaller than they are for $\lambda=469 \mathrm{~nm}$. The mean transmittance enhancement is 0.016 for $\tau(550)=0.04$ and increases to 0.023 for $\tau(550)=0.30$ (simulations for the spring albedo pattern, $\vartheta=60^{\circ}$ and $\alpha=180^{\circ}$ ).

In the Hornsund fjord, the transmittance and the transmittance enhancement change only weakly with aerosol optical thickness but they strongly depend on a location in the fjord. The spatial variability in transmittance due to the land impact over the fjord is comparable to or higher than the variability in transmittance caused by typical variations in aerosol optical thickness in the Arctic. This must be kept in mind in both a study of aerosol radiative forcing based on surface irradiance measurements and an extrapolation of point coastal measurements of solar radiation to a larger area. In our simulations we assumed that the fjord was free of ice. Ice-free periods in Arctic fjords are expected to be longer and more frequent in a warming Arctic even in winter and spring. Nowadays, however, some form of ice is usually present in the Hornsund fjord. It may be ice of glacial origin or allochthonic and autochthonic sea ice. The type of ice, its concentration and extent are all strongly variable (e.g. Styszyńska and Kowalczyk 2007; Styszyńska and Rozwadowska 2008). In summer and early autumn the ice on the fjord is limited to a small amount of drifting glacier ice (growlers and bergy bits). Including sea ice in our simulations would result in an increase in the transmittance enhancement over the fjord. Enhancement values similar to those observed on snow-covered glaciers are expected when the whole fjord is covered with a continuous sheet of snow-covered ice. However, the spatial variability in irradiance transmittance over the fjord would be lower than it is on the ice-free fjord.

The spectral shortwave radiative forcing (for $\lambda=469 \mathrm{~nm}$ ) of Arctic aerosols is typically negative. Its magnitude over the Hornsund fjord (the mean for the fjord area) for the spring land albedo pattern $\vartheta=60^{\circ}$ and $\alpha=180^{\circ}$ varies from $<0.01$ of the TOA irradiance for the summer background value of the aerosol optical thickness $(\tau(550)=0.05)$ to 0.066 for the high aerosol optical thickness $(\tau(550)=0.3)$ of weakly absorbing aerosols. The magnitude of the $A R F_{\text {rel }}(\lambda=469 \mathrm{~nm})$ averaged over the whole fjord is lower than it is for the open ocean under the same conditions but the difference is small. It does not exceed 0.003 for the aerosol optical range from 0.04 to 0.15 , typical of the Arctic. For the individual 
subregions the differences of $A R F_{\text {rel }}(\lambda=469 \mathrm{~nm})$ from the ocean value exceed \pm 0.01 only for large solar zenith angles $\left(\vartheta=79^{\circ}\right)$.

Snow-covered land surrounding the fjord increases TOA radiances in channels 469 and $858 \mathrm{~nm}$ of MODIS over the fjord. The influence of the land on the TOA radiance over the fjord in channel $469 \mathrm{~nm}$ is comparable to the impact of an increase in aerosol optical thickness of over $100 \%$, and in lateral fjords of up to several hundred \%. For channel $858 \mathrm{~nm}$, a larger solar zenith angle and/or summer pattern of the land surface albedo the increase in TOA radiance is less, though still considerable. The increase in TOA radiance is wavelengthdependent. In effect, the TOA spectrum over the fjord turns more bluish, which may strongly affect retrievals of aerosol optical properties over the water in the coastal region of the Arctic near glaciers and snow-covered land.

Acknowledgements. - This research was carried out within the framework of Polish Research Project NN307315436 funded by the Polish Ministry of Science and Higher Education in 2009-2011, statutory research funds from the Institute of Oceanology PAS, Sopot and research project Pol-Nor/196911/38/2013 of the Polish-Norwegian Research Programme. The authors are very grateful to the reviewers: Assoc. Prof. Jolanta Kuśmierczyk-Michulec and Prof. Jacek Piskozub for their helpful comments. The authors express their gratitude to the Alfred Wegener Institute for providing radio sounding data from Ny-Ålesund. The PI for the radio soundings in Ny-Ålesund is Marion Maturilli. The authors gratefully acknowledge the Academic Computer Centre in Gdańsk - TASK for providing computational facilities. The computations were partly done by means of the Galera computer cluster at TASK.

\section{References}

ARMBRUSTER W. and FISCHER J. 1996. Improved method of exponential sum fitting of transmissions to describe the absorption of atmospheric gases. Applied Optics 35: 1931-1941.

BÉLANGER S., EHN J.K. and BABIN M. 2007. Impact of sea ice on the retrieval of water-leaving reflectance, chlorophyll a concentration and inherent optical properties from satellite ocean color data. Remote Sensing of Environment 111: 51-68.

Berk A., Anderson G.P., Acharya P.K., Hoke M.L., Chetwynd J.H., Bernstein L.S., ShetTLE E.P., MATTHEW M.W. and ALDER-GOLDEN S.M. 2003. MODTRAN4. Version 3. Revision 1. Users manual. Air Force Research Laboratory, Hanscom, AFB, MA: 98 pp.

CHEN Y., HALl A. and LiOU K.N. 2006. Application of three-dimensional solar radiative transfer to mountains. Journal of Geophysical Research 111, D21111.

CHOU M.-D., 1992. A solar radiation model for use in climate studies. Journal of the Atmospheric Sciences 49: 762-772.

D'Almeida G.A., KoePKe P. and Shettle E.P. 1991. Atmospheric aerosols. Global climatology and radiative characteristics. A. DEEPAK Publishing, Hampton: 561 pp.

Degünther M., Meerkötter R., Albold A. and SeckmeYer G. 1998. Case study of the influence of inhomogeneous surface albedo on UV irradiance. Geophysical Research Letters 25: $3587-3590$. 
DEGÜNTHER M. and MEERKÖTTER R. 2000. Influence of inhomogeneous surface albedo on UV irradiance: effect of a stratus cloud. Journal of Geophysical Research 105(D18): 22755-22761.

HENYEY L.G. and GREENSTEIN J.L. 1941. Diffuse radiation in the galaxy. The Astrophysical Journal 93: 70-83.

Huber M., Blumthaler M., Schreder J., Schallhart B. and Lenoble J. 2004. Effect of inhomogeneous surface albedo on diffuse UV sky radiance at a high-altitude site. Journal of Geophysical Research 109: D08107.

IWABUCHI H. 2006. Efficient Monte Carlo methods for radiative transfer modelling. Journal of the Atmospheric Sciences 63: 2324-2339.

JÄKEL E., WENDISCH M. and MAYER B. 2013. Influence of spatial heterogeneity of local surface albedo on the area-averaged surface albedo retrieved from airborne irradiance measurements. Atmospheric Measurement Techniques 6: 527-537.

Kreuter A., Buras R., Mayer B., WebB A., Kift R., Bais A., Kourementi N. and BlumthalER M. 2014. Solar irradiance in the heterogeneous albedo environment of the Arctic coast: measurements and a 3-D model study. Atmospheric Chemistry and Physics 14: 5989-6002.

Kylling A., Persen T., Mayer B. and Svenøe T. 2000. Determination of an effective spectral surface albedo from ground-based global and direct UV irradiance measurement. Journal of Geophysical Research 105: 4949-4959.

KYLLING A. and MAYER B. 2001. Ultraviolet radiation in partly snow covered terrain: observations and three-dimensional simulations. Geophysical Research Letters 28: 3665-3668.

LEE W.-L., LIOU K.N. and HALL A. 2011. Parameterization of solar fluxes over mountain surfaces for application to climate models. Journal of Geophysical Research 116: D01101.

LENOBLE J. 2000. Influence of the environment reflectance on the ultraviolet zenith radiance for cloudless sky. Applied Optics 39: 4247-4254.

LENOBLE J., KYLLING A. and SMOLSKAIA I. 2004. Impact of snow cover and topography on ultraviolet irradiance at the Alpine station of Briancon. Journal of Geophysical Research 109: D16209.

LIOU K.N., LEE W.-L. and HALL A. 2007. Radiative transfer in mountains: application to the Tibetan Plateau. Geophysical Research Letters 34: L23809.

LUBIN D., RICCHIAZZI P., PAYTON A. and GAUTIER C. 2002. Significance of multidimensional radiative transfer effects measured in surface fluxes at an Antarctic coastline. Journal of Geophysical Research 107: 4387.

Marchuk G., Mikhailov G., Nazaraliev M., Darbinjan R., Kargin B. and Elepov B. 1980. The Monte Carlo methods in atmospheric optics. Springer-Verlag, New York: 208 pp.

Markowicz K.M., Flatau P.J., RemiszewsKa J., WiteK M., Reid E.A., ReiD J.S., Bucholtz A. and HOLBEN B. 2008. Observations and modeling of the surface aerosol radiative forcing during UAE2. Journal of the Atmospheric Sciences 65: 2877-2891.

MARSHAK A. and DAVIS A.B. (EDS.) 2005. 3D radiative transfer in cloudy atmospheres. SpringerVerlag, Berlin-Heidelberg-New York: 686 pp.

MarshaK A., Davis A., Wiscombe W. and Titov G. 1995. The verisimilitude of the independent pixel approximation used in cloud remote sensing. Remote Sensing of Environment 52: 71-78.

MarshaK A., Wen G., Coakley J.A., Remer L.A., Loeb N.G. and Cahalan R.F. 2008. A simple model for the cloud adjacency effect and the apparent bluing of aerosols near clouds. Journal of Geophysical Research 113: D14S17.

MAYER B. 1999. I3RC phase 1 results from the MYSTIC Monte Carlo model. In: Proceedings of the I3RC workshop. Tucson, Arizona, November 17-19, 1999: 1-6. 
Moskalik M., Tęgowski J., Grabowiecki P. and ŻUlichowsKa M. 2014. Principal Component and Cluster Analysis for determining diversification of bottom morphology based on bathymetric profiles from Brepollen (Hornsund, Spitsbergen). Oceanologia 56: 59-84.

NiEDŹWIEDŹ T. and STYSZYŃSKA A. 2013. Snow cover at the Hornsund station. In: Marsz A. and Styszyńska A. (eds) Climate and Climate Change at Hornsund, Svalbard. The Publishing House of Gdynia Maritime University, Gdynia: 367-372.

Petkov B., Tomasi C., Vitale V., di Sarra A., Bonasoni P., Lanconelli C., Benedetti E., Sferlazzo D., DiÉmoz H., Agnesod G. and SAntaguida R. 2010. Ground-based observations of solar radiation at three Italian sites, during the eclipse of 29 March, 2006: Signs of the environment impact on incoming global irradiance. Atmospheric Research 96: 131-140.

Remer L.A., Kaufman Y.J., TAnRe D., Mattoo S., Chu D.A., Martins J.V., Li R.R., ICHOKU C., LeVy R.C., Kleidman R.G., EcK T.F., Vermote E. and Holben B.N. 2005. The MODIS aerosol algorithm, products, and validation. Journal of the Atmospheric Sciences 62: 947-973.

RICCHIAZZI P. and GAUTIER C. 1998. Investigation of the effect of surface heterogeneity and topography on the radiation environment of Palmer Station, Antarctica, with a hybrid 3-D radiative transfer model. Journal of Geophysical Research 103: 6161-6176.

RicCHIAZZI P., YANG S., GAUTIER C. and SOwLE D. 1998. SBDART: A research and teaching software tool for plane-parallel radiative transfer in the Earth's atmosphere. Bulletin of the American Meteorological Society 79: 2101-2114.

RozWADOWSKa A. and CAHALAN R. 2002. Plane-parallel biases computed from inhomogeneous Arctic clouds and sea ice. Journal of Geophysical Research 107: 4387.

RozWADOWSKA A. and SOBOLEWSKI P. 2010. Variability in aerosol optical properties at Hornsund, Spitsbergen. Oceanologia 52: 599-620.

Rozwadowska A., Zieliński T., Petelski T. and Sobolewski P. 2010. Cluster analysis of the impact of air back-trajectories on aerosol optical properties at Hornsund, Spitsbergen. Atmospheric Chemistry and Physics 10: 877-893.

ROZWADOWSKA A. and GÓRECKA I. 2012. The impact of a non-uniform land surface on the radiation environment over an Arctic fjord - a study with a 3D radiative transfer model for stratus clouds over the Hornsund fjord, Spitsbergen. Oceanologia 54: 509-543.

Smolskaia I., MAsSerot D., Lenoble J., Brogniez C. and DE la CAsinière A. 2003. Retrieval of the ultraviolet effective snow albedo during 1998 winter campaign in the French Alps. Applied Optics 42: 1583-1587.

SPADA F., KROL M.C. and StAMMES P. 2006. McSCIA: application of the Equivalence Theorem in a Monte Carlo radiative transfer model for spherical shell atmospheres. Atmospheric Chemistry and Physics 6: 4823-4842.

Stempniewicz L., Darecki M., Trudnowska E., BŁachowiak-SamoŁyK K., Boehlke R., Jakubas D., Keslinka-Nawrot L., Kidawa D., SAGan S. and WojczUlanis-Jakubas K. 2013. Visual prey availability and distribution of foraging little auks (Alle alle) in the shelf waters of West Spitsbergen, Polar Biology 36: 949-955.

STYSZYŃSKA A. 2013. Results of Observations. In: Marsz A. and Styszyńska A. (eds) Climate and Climate Change at Hornsund, Svalbard. The Publishing House of Gdynia Maritime University, Gdynia: 321-366.

STYSZYŃSKA A. and KowAlCZYK M. 2007. Ice condition in Hornsund and its foreshore (SW Spitsbergen) during winter season 2005-2006. Problemy Klimatologii Polarnej 17: 147-158 (in Polish).

STYSZYŃSKA A. and RozWADOWSKA A. 2008. Ice condition in Hornsund and its foreshore (SW Spitsbergen) during winter season 2006/2007. Problemy Klimatologii Polarnej 18: 141-160 (in Polish). 
Szymanowski M., Kryza M., MigaŁa K., Sobolewski P. and Kolondra L. 2008. Preliminary results of GIS-based solar radiation model for Hornsund area, SW Spitsbergen. The dynamics and mass budget of Arctic glaciers In: Extended abstracts of workshop and GLACIODYN (IPY) meeting, 29-31 January 2008, Obergurgl (Austria), IASC Working group on Arctic Glaciology. Institute of Marine Atmospheric Research, Utrecht University, Utrecht: 126-128.

ThOMAS G. and StAMnes K. 2002. Radiative transfer in the atmosphere and ocean, Cambridge University Press, Cambridge: 517 pp.

VÁRNAI T. and MARSHAK A. 2009. MODIS observations of enhanced clear sky reflectance near clouds. Geophysical Research Letters 36: L06807.

Received 7 September 2016

Accepted 27 February 2017 